\title{
THE IMPACT OF FRAILTY ON THE RELATIONSHIP BETWEEN LIFE-SPACE MOBILITY AND QUALITY OF LIFE IN OLDER ADULTS DURING THE COVID-19 PANDEMIC
}

\author{
M.D. SARAIVA ${ }^{1, *}$, D. APOLINARIO ${ }^{1,2, *}$, T.J. AVELINO-SILVA ${ }^{1}$, C. DE ASSIS MOURA TAVARES ${ }^{3}$, \\ I.F. GATTÁS-VERNAGLIA ${ }^{4}$, C. MARQUES FERNANDES ${ }^{3}$, L.M. RABELO ${ }^{3}$, \\ S. TAVARES FERNANDES YAMAGUTI², T. KARNAKIS ${ }^{4}$, R. KALIL-FILHO $^{3}$, W. JACOB-FILHO ${ }^{1}$, \\ M.J. ROMERO ALIBERTI ${ }^{1,5}$
}

\begin{abstract}
1. Laboratorio de Investigacao Medica em Envelhecimento (LIM-66), Servico de Geriatria, Hospital das Clinicas HCFMUSP, Faculdade de Medicina, Universidade de Sao Paulo, Sao Paulo/SP - Brazil; 2. Hospital do Coracao (HCor), Associacao Beneficente Siria, São Paulo/SP - Brazil; 3. Instituto do Coração (InCor) do Hospital das Clinicas da FMUSP, Sao Paulo/ SP - Brazil; 4. Instituto do Cancer do Estado de Sao Paulo (ICESP) - Octavio Frias de Oliveira, Sao Paulo/SP - Brazil; 5. Instituto de Ensino e Pesquisa, Hospital Sirio-Libanes, São Paulo/SP - Brazil; * Both authors contributed equally to this work. Corresponding author: Márlon Juliano Romero Aliberti, Laboratorio de Investigacao Medica em Envelhecimento (LIM-66), Servico de Geriatria, Hospital das Clinicas, Faculdade de Medicina, Universidade de Sao Paulo. Av. Dr. Eneas de Carvalho Aguiar 155, $8^{\circ}$ andar, Clinica Medica, LIM-66, Cerqueira Cesar, Sao Paulo - SP, 05403-000, Brazil. Tel.: +55-11-26618116. E-mail address: maliberti@usp.br
\end{abstract}

\begin{abstract}
Background: The COVID-19 pandemic has led to abrupt restrictions of life-space mobility. The impact of shelter-in-place orders on older adults' health and well-being is still unclear. Objective: To investigate the relationship between life-space mobility and quality of life (QoL) in older adults with and without frailty during the COVID-19 pandemic. Design: Multicenter prospective cohort study based on structured telephone interviews. Setting: Four geriatric outpatient clinics in the metropolitan area of Sao Paulo, Brazil. Participants: 557 community-dwelling adults aged 60 years and older. Measurements: The Life-Space Assessment was used to measure community mobility before and during the COVID-19 pandemic, and a previously validated decrease of $\geq 5$ points defined restricted life-space mobility. Frailty was assessed through the FRAIL (fatigue, resistance, ambulation, illnesses, and loss of weight) scale. The impact of shelter-in-place orders on QoL was evaluated with the question «How is the COVID-19 pandemic affecting your QoL?», to which participants could respond «not at all», «to some extent», or «to a great extent». We used ordinal logistic regressions to investigate the relationship between restricted life-space mobility and impact on QoL, adjusting our analyses for demographics, frailty, comorbidities, cognition, functionality, loneliness, depression, and anxiety. We explored whether frailty modified the association between life-space mobility and impact on QoL. Results: Participants were on average $80 \pm 8$ years old, $65 \%$ were women, and 33\% were frail. The COVID-19 quarantine led to a restriction of community mobility in $79 \%$ of participants and affected the QoL for $77 \%$ of participants. We found that restricted life-space mobility was associated with impact on $\mathrm{QoL}$ in older adults during the pandemic, although frailty modified the magnitude of the association $(\mathrm{P}$-value for interaction $=0.03$ ). Frail participants who experienced restricted life-space mobility had twice the odds of reporting an impact on QoL when compared with non-frail individuals, with respective adjusted odds ratios of 4.20 (95\% CI=2.36-7.50) and 2.18 (95\% CI=1.33-3.58). Conclusion: Older adults experienced substantial decreases in life-space mobility during the COVID-19 pandemic, and this unexpected change impacted their QoL. Providers should be particularly watchful for the consequences of abrupt life-space restrictions on frail individuals.
\end{abstract}

Key words: Frailty, life-space mobility, quality of life, COVID-19, quarantine.

\section{Introduction}

The COVID-19 pandemic has produced far-reaching effects on health, economy, and behavior all over the world. At the beginning of October 2020, ten months following the first report of COVID-19, about 34 million people have been infected, and more than one million people have died from the disease worldwide (1). Brazil is currently one of the epicenters of the pandemic, following the United States in the number of cases and deaths (1).

Although most people are asymptomatic or oligosymptomatic when infected by the new coronavirus (SARS-CoV-2), older adults are disproportionately vulnerable to severe forms and death by COVID-19 (2-4). As evidencebased therapeutic measures and vaccines are yet to be Received October 2, 2020 developed, most countries have adopted physical distancing as the primary strategy to limit the transmission of the disease (5).

Rigorous distancing can be a powerful weapon to fight the new coronavirus spread. However, community-dwelling older adults may experience more difficulties in adapting to sudden lifestyle changes, especially in the context of frailty $(6,7)$. The COVID-19 quarantine has already been associated with the exacerbation of loneliness and psychological distress (8-10), but physical health and well-being can also be affected by the current recommendations. Moreover, freedom and independence to come and go are inherently important to every person and have been recognized as vital determinants of healthy aging $(11,12)$.

Since mobility is viewed as an essential component of wellbeing by many older adults, strategies to measure it have been
Published online November 17, 2020, http://10.1007/s12603-020-1532-z 


\section{THE JOURNAL OF NUTRITION, HEALTH \& AGING}

proposed, consolidating the concept of life-space mobility (13, 14). Life-space is characterized by the movement that extends from within one's home to beyond their town or region, and it can be evaluated by instruments like the Life-Space Assessment (LSA) (15). The LSA is a well-validated tool that measures how much a person moves in the community, maintains social relationships and roles, exploits community amenities, and participates in meaningful activities $(12,13)$. LSA scores have been shown to predict multiple adverse outcomes (e.g., falls, nursing home admissions, mortality) in community-dwelling older adults (16-22).

Previous studies have demonstrated that declining life-space mobility is associated with lower quality of life (23). However, the artificial and abrupt changes in mobility determined by the COVID-19 pandemic represent an entirely new scenario, and their impact on the health and well-being of older adults with and without frailty is still unknown (24). Therefore, we aimed to investigate whether a sudden decrease in life-space mobility during the COVID-19 pandemic affected the quality of life of older adults. We also explored whether frailty modified the association between life-space mobility and impact on quality of life.

\section{Methods}

\section{Study design and participants}

This study is an ongoing multicenter prospective cohort study being conducted in the metropolitan area of Sao Paulo, Brazil. Our cohort was recruited to observe the impact of the COVID-19 pandemic on the health trajectories of communitydwelling older adults. Since March 2020, when a statewide quarantine was declared in Sao Paulo, our team of researchers has been working in four geriatric outpatient clinics to follow the mental and physical health of the participants. Three of our study sites [Instituto Central (IC), Instituto do Coracao (InCor), and Instituto do Cancer do Estado de Sao Paulo (ICESP)] belong to the hospital complex of Hospital das Clinicas, University of Sao Paulo Medical School (HCFMUSP), the largest academic medical center in Latin America. HCFMUSP is a tertiary public hospital that provides integrated care for 420,000 older patients residing in the greater Sao Paulo area. Our fourth study site was Hospital do Coracao (HCor), a private philanthropic hospital distinguished in providing patientcentered care for frail older adults in Sao Paulo.

We recruited community-dwelling older adults aged 60 years and over, followed at the four geriatric outpatient clinics. We reviewed electronic databases to identify eligible candidates, using previously recorded information from comprehensive geriatric assessments. We did not invite patients whose database records were incomplete. Long-term facility residents and patients with overt dementia, immobility, or severe dependence in performing activities of daily living (ADLs) were considered ineligible (25). We also excluded candidates who were unable to communicate in the telephone effectively (e.g., hearing loss, aphasia), who could not be reached after three contact attempts, who were hospitalized on the inclusion assessment, and who refused to consent participation.

Written or audio-recorded consent was obtained from participants. Patients who scored 9 points or more in the Patient Health Questionnaire-4 (PHQ-4) were offered additional psychological support following the interviews. Our interviewers also examined signs and symptoms of COVID19 , asked about health services utilization, and reinforced the importance of social distancing and protective measures during the pandemic.

\section{Measurements}

In April, we completed detailed telephone interviews to collect baseline information, and the first follow-up assessment from our participants (the follow-up procedures and design of our cohort study are detailed in the Supplementary Figure 1). A team of trained research assistants completed the telephone interviews directly with participants. Medical investigators adjudicated the quality of the collected data. Data were collected and managed using the Research Electronic Data Capture platform (REDCap) (26).

Our interviews lasted an average of 20 minutes and included questions on whether the participants were following the news about the COVID-19 pandemic, their concerns about the situation, compliance to measures against contamination, influenza vaccine status, and living arrangements (27). The impact of quarantine on their physical and mental health was evaluated using the following instruments:

(1) International Physical Activity Questionnaire (IPAQ) Short Form (28), a brief questionnaire used to evaluate the frequency and time spent in moderate to vigorous physical activity, including walks, housework, and leisure activities, in a typical week.

(2) Life-Space Assessment (LSA) (29), a self-reported measure of life-space mobility. It estimates the distance traveled over the previous weeks in areas as small as one's bedroom, up to more distant places in the city or region. LSA also measures the frequency with which each life-space level is attained, and evaluates the independence of movement (i.e., the necessity of an assistive device or assistance from another person). LSA has been validated for telephone application and has scores ranging from 0 to 120 , with higher scores indicating greater mobility $(15,30)$. Previous studies have defined variations of five or more points in LSA scores as significant (13).

(3) 3-item UCLA Loneliness Scale (UCLA-3) (31), a threequestion scale on «lacking companionship», «feeling left out» and «feeling isolated from others». Responses were scored as 1 (hardly ever), 2 (some of the time), or 3 (often), and a final score was generated from the sum of the items. Participants with scores of $\geq 6$ were defined as having high levels of loneliness.

(4) 4-Item Patient Health Questionnaire (PHQ-4) (32), which contains two questions on anxiety symptoms [Generalized 


\section{COVID-19 PANDEMIC AND QUALITY OF LIFE}

Anxiety Disorder 2-item (GAD-2)] and two questions on depressive symptoms [Patient Health Questionnaire 2-item (PHQ-2)]. Each question is answered according to a Likert scale based on how often the symptoms were present in the previous two weeks. The anxiety and depression subscales have scores ranging from 0 to 6 , with scores $\geq 3$ indicating significant symptoms in the corresponding domain.

In order to assess the impact of the COVID-19 quarantine on their life-space mobility and physical activity levels, we asked participants to complete the LSA and the IPAQ Short Form using two time-points: before the quarantine, defined as February 2020 (the quarantine started in March 2020 in Sao Paulo), at the baseline interview; and during the quarantine, defined as the two weeks preceding our first follow-up interview.

We reviewed medical records to confirm or collect data on demographic characteristics (age, sex, marital status, education, neighborhood), medical history, cognition [10-point cognitive screener (10-CS)] (33), functional status (Katz index - ADLs) (33), and frailty. Frailty was evaluated using the FRAIL scale, a well-validated screening tool that includes five mnemonic questions on fatigue, resistance, ambulation, illnesses, and loss of weight. FRAIL scores range from 0 to 5 , with scores $\geq 3$ classifying older adults as frail $(35,36)$.

\section{Outcome}

Our primary outcome was quality of life, evaluated with the following question: «How is the coronavirus pandemic affecting your quality of life?». Possible responses were «not at all», «to some extent», and «to a great extent», defining a three-level outcome with the categories «no impact», «minor impact», and «major impact», respectively (37). We used a single measure to capture how people perceive and react to the transformations imposed by the COVID-19 pandemic in their health status and other nonmedical aspects of their lives (38). Quality of life is something that is perceived by each person individually. A single global rating can reflect the different values and preferences of individuals, offering a sensible and easy-to-apply approach to measuring the quality of life, particularly in the context of life transitions or to evaluate the quality of life in specific situations $(37,39)$. Besides their simplicity, single-item assessments also have the advantage of being better validated for telephone interviews (40).

\section{Statistical analyses}

We compared variables according to the three categories of quality of life impact (no impact, minor impact, major impact), using the Kruskal-Wallis test for interval variables and the exact Fisher test for categorical variables.

We used ordinal logistic regression models to investigate which factors were associated with the impact of the COVID19 quarantine on the quality of life of our population. Our primary independent variable was restricted life-space mobility, defined as a decrease of $\geq 5$ points in LSA scores between measurements (before vs. during the quarantine). We adjusted the regressions for possible confounders, including demographics, comorbidities, cognition, functional status, frailty, loneliness, anxiety, and depression. We tested a preplanned interaction between frailty status and restricted life-space mobility for the impact on the quality of life (41). Variance inflation factors (VIF) did not detect multicollinearity in our models.

Statistical analyses were performed using Stata version 15.1 (Stata Corp. LP, College Station, TX, USA). All statistical tests were two-tailed, and an alpha level $<0.05$ was accepted to indicate statistical significance.

\section{Results}

A total of 886 individuals were pre-screened from our databases as potential candidates for participation. After eligibility assessment, 145 were excluded for circumstances that precluded telephone interviews (mostly severe hearing loss), 104 could not be reached after three contact attempts, 36 refused participation, and 17 were hospitalized when contacted. Finally, 27 were excluded for missing data. Therefore, we included 557 participants from the four study sites for complete-case data analyses (IC=316; InCor $=113$; HCor=95; ICESP=33). Figure 1 shows the broad distribution of our population in the metropolitan area of Sao Paulo, according to the zip code and study site.

\section{Figure 1}

Distribution of the study population in the metropolitan area of Sao Paulo, according to zip code and study site $(n=557)$

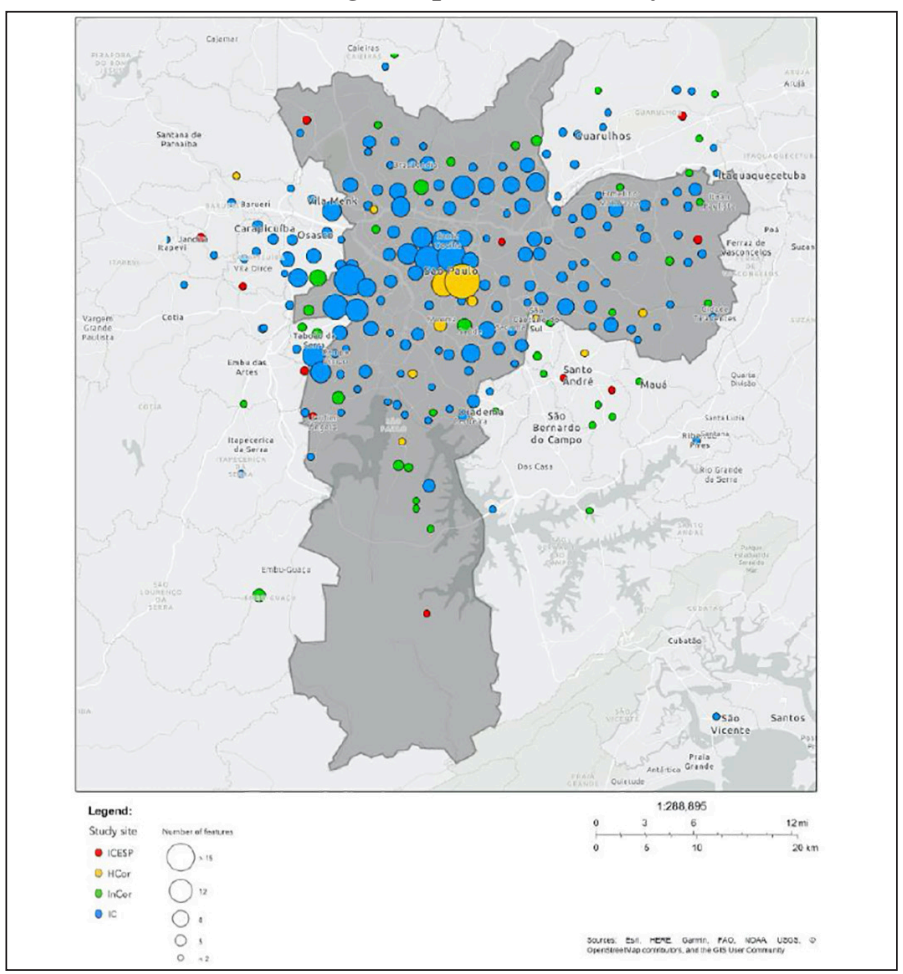

HCor $=$ Hospital do Coracao; IC = Instituto Central; InCor = Instituto do Coracao; ICESP = Instituto do Cancer do Estado de Sao Paulo 
THE JOURNAL OF NUTRITION, HEALTH \& AGING

Table 1

Characteristics of participants according to the impact of the COVID-19 quarantine on quality of life

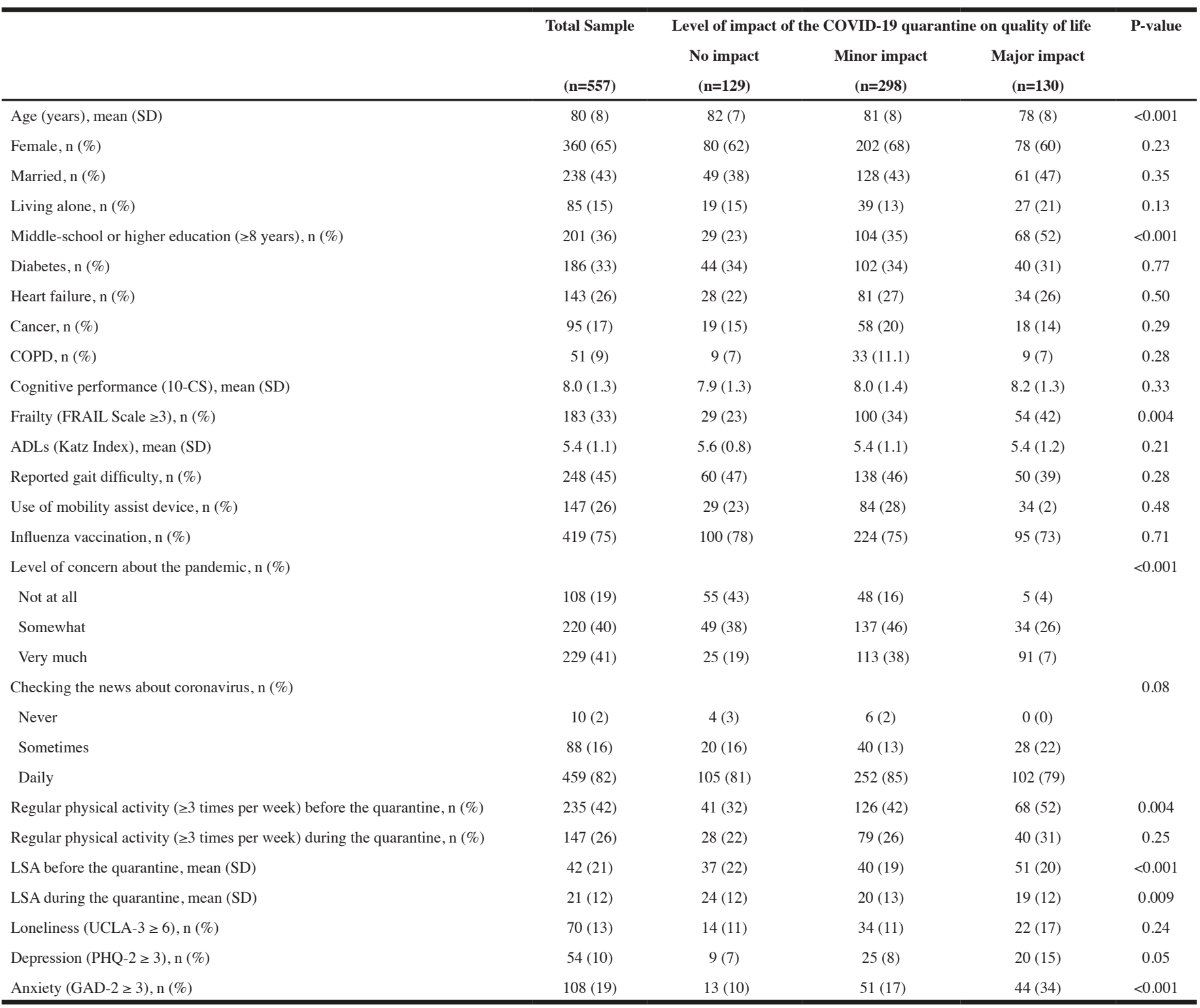

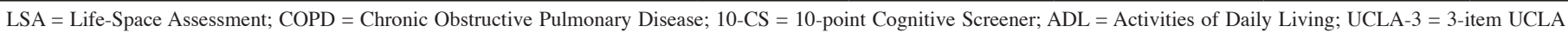

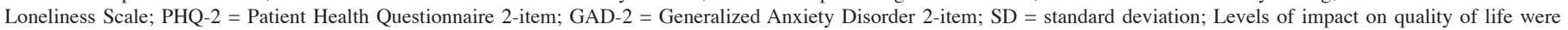
compared using the Kruskal-Wallis test for interval variables and the Fisher test for categorical variables.

We observed a mean age of 80 years (range 60-100) years, $65 \%$ were women, $64 \%$ had less than eight years of formal education, and $15 \%$ were living alone. Overall, $33 \%$ of our participants were frail and, although they were all able to walk, $45 \%$ reported gait difficulties, and $26 \%$ used assistive devices. Descriptive statistics are presented in Table 1.

When questioned about the COVID-19 pandemic, $81 \%$ reported being somewhat or very worried, and $82 \%$ were checking the news about COVID-19 every day. Compliance with preventive measures against the disease was generally good: $95 \%$ were avoiding going out, $87 \%$ were practicing social distancing, $80 \%$ had increased hand-washing frequency, $75 \%$ had been vaccinated against influenza in 2020 , and $68 \%$ had intensified their environment sanitization routines.

The prevalence of depression (10\%) and loneliness (13\%) was compatible with what is usually observed in communitydwelling older adults. Conversely, the prevalence of anxiety was higher, affecting $19 \%$ of our sample. When asked about the impact of the COVID-19 pandemic on their quality of life, 54\% of our participants replied that the pandemic had affected them to some extent, while $23 \%$ replied not to have been affected at all, and 23\% to have been affected to a great extent. As shown 


\section{COVID-19 PANDEMIC AND QUALITY OF LIFE}

in Table 1, participants who reported a major impact on quality of life were younger, more educated, and had higher levels of anxiety. We did not observe differences in the impact of the COVID-19 quarantine on quality of life according to sex, living arrangement, comorbidities, cognition, physical performance, or frailty.

We verified substantial changes in life-space mobility during the quarantine, in our population. The proportion of participants who reported leaving their homes at least once a week for external activities dropped from $74 \%$ before the quarantine to $19 \%$ during the quarantine. Furthermore, the proportion of individuals who left their houses every day went from $29 \%$ to $2 \%$. Correspondingly, the mean LSA scores dropped from 42 points before the quarantine to 21 points during the quarantine $(\mathrm{P}<0.001)$. Most of our patients $(79 \%)$ decreased their life-space mobility levels in five points or more, fulfilling the criteria for restricted life-space mobility. Physical activity markedly decreased before vs. during the quarantine as well, from $42 \%$ to $26 \%$ of older adults doing regular physical activity at least three times per week $(\mathrm{P}<0.001)$.

We confirmed our hypothesis that the restriction of lifespace mobility would be associated with the impact of the COVID-19 quarantine on the quality of life of communitydwelling older adults (Figure 2). In an adjusted regression model, restricted life-space mobility was associated with higher levels of impact on quality of life, with an odds ratio (OR) of 2.18 [95\% confidence interval $(95 \% \mathrm{CI})=1.33-3.58$ ] . Younger age, higher education, and the presence of anxiety were also independently associated with higher levels of impact on quality of life (Table 2).

\section{Figure 2}

Life-space assessment scores in community-dwelling older adults, before and during the COVID-19 quarantine $(n=557)$

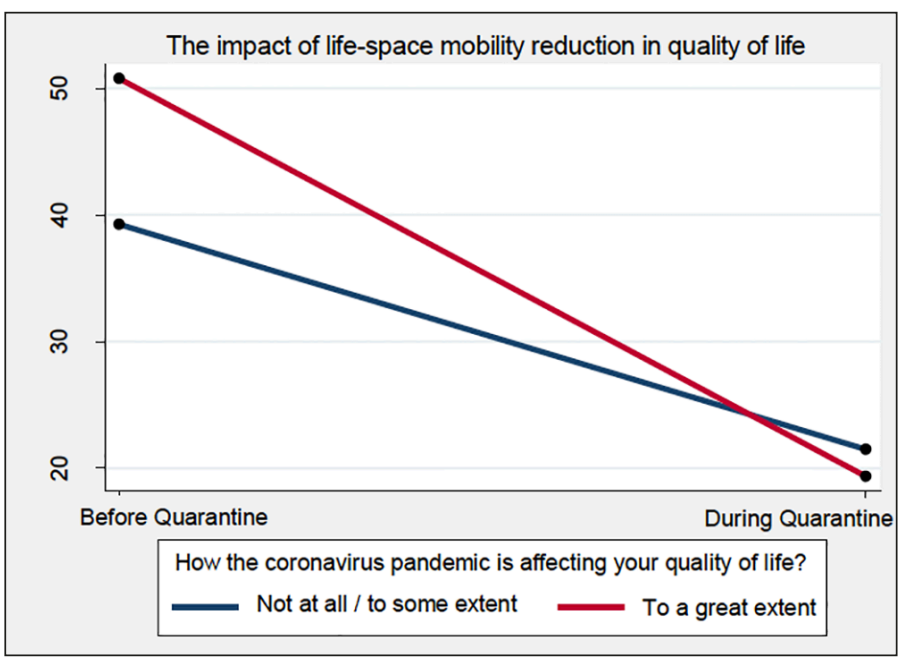

Our preplanned interaction analyses revealed that frailty modified the effect of life-space restriction on the study outcome ( $\mathrm{P}$-value for interaction=0.03), indicating that frail older adults had a significantly higher risk of having their quality of life affected by restricted life-space mobility during the pandemic (Table 3 ).

Table 2

Factors associated with the impact of the COVID-19 pandemic on the quality of life of community-dwelling older adults $(\mathrm{n}=557)$

\begin{tabular}{|c|c|c|}
\hline & \multicolumn{2}{|c|}{ Odds Ratio (95\% Confidence Interval) } \\
\hline & Unadjusted Model & Adjusted Model \\
\hline $\begin{array}{l}\text { Restricted life-space mobility ( } \geq 5 \text {-point } \\
\text { decrease in LSA) }\end{array}$ & $2.60(1.63-4.17)$ & $2.18(1.33-3.58)$ \\
\hline Frailty (FRAIL Scale $\geq 3$ ) & $0.83(0.39-1.77)$ & $0.72(0.33-1.61)$ \\
\hline $\begin{array}{l}\text { Interaction: restricted life-space } \\
\text { mobility*frailty }\end{array}$ & $2.43(1.04-5.69)$ & $2.66(1.08-6.56)$ \\
\hline Age (years) & & $0.97(0.95-0.99)$ \\
\hline Female sex & & $1.00(0.66-1.52)$ \\
\hline $\begin{array}{l}\text { Middle-school or higher education ( } \geq 8 \\
\text { years) }\end{array}$ & & $1.93(1.32-2.83)$ \\
\hline Married & & $1.17(0.77-1.78)$ \\
\hline Living alone & & $1.33(0.79-2.23)$ \\
\hline Diabetes & & $0.80(0.76-1.15)$ \\
\hline Heart Failure & & $1.29(0.88-1.91)$ \\
\hline Cancer & & $1.16(0.74-1.81)$ \\
\hline COPD & & $0.94(0.53-1.66)$ \\
\hline Cognitive performance (10-CS score) & & $1.11(0.98-1.25)$ \\
\hline ADL (Katz Index) & & $0.91(0.77-1.08)$ \\
\hline Loneliness (UCLA-3 score) & & $1.13(0.98-1.30)$ \\
\hline Depression (PHQ-2 score) & & $0.99(0.84-1.18)$ \\
\hline Anxiety (GAD-2 score) & & $1.43(1.24-1.64)$ \\
\hline
\end{tabular}

LSA $=$ Life-Space Assessment COPD $=$ Chronic Obstructive Pulmonary Disease; 10-CS = 10-point Cognitive Screener; ADL = Activities of Daily Living; UCLA-3 = 3-item UCLA Loneliness Scale; PHQ-2 = Patient Health Questionnaire 2-item; GAD-2 = Generalized Anxiety Disorder 2-item; Estimates were calculated using ordinal logistic regression model; the dependent variable was the impact on quality of life during the COVID-19 quarantine, categorized in three levels (no impact, minor impact, major impact).

\section{Discussion}

In this multicenter cohort study from the Sao Paulo metropolitan area, we found that four in five communitydwelling older adults experienced a clinically significant reduction in their life-space mobility as a result of the stayat-home orders during the COVID-19 pandemic. Notably, we verified that restrictions in life-space mobility influenced the impact of the COVID-19 quarantine on older adults' quality of life, particularly among those who were frail. Understanding how this phenomenon might affect the health and well-being of older people with and without frailty is a crucial step towards the mitigation of some of the negative consequences of the physical distancing measures.

Life-space mobility represented an essential aspect of environmental complexity in older adults (42). Despite not 


\section{THE JOURNAL OF NUTRITION, HEALTH \& AGING}

Table 3

Modification effect of frailty on the association between restricted life-space mobility and the impact of the COVID-19 quarantine on the quality of life of older adults $(n=557)$

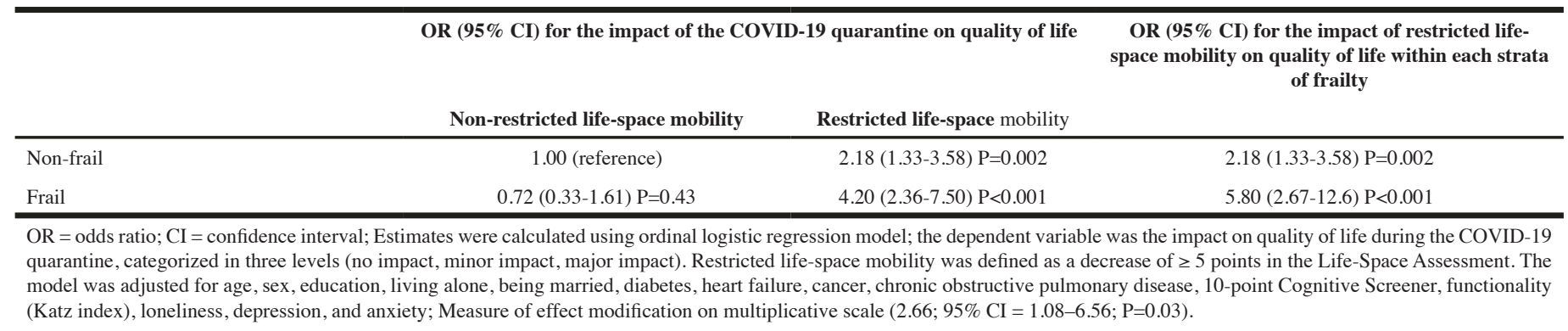

being a direct measure of physical performance, LSA has been described as a comprehensive representation of functioning and a strong predictor of adverse outcomes in older age, including falls, cognitive decline, hospitalization, institutionalization, and death (42-46). While physical performance (such as walking ability) accounts for a significant portion of its final score, LSA is strongly associated with several other factors that influence mobility, including social connections, cognitive performance, personality traits, and mental health $(13,15)$. All these aspects are crucial for the well-being of older adults.

In this study, we noticed a massive decrease of life-space mobility in a short period of time. The mean LSA score reduced from 42 (before the quarantine) to 21 (during the first weeks of the quarantine), a drop similar to that encountered in older adults who suffered a hip fracture (22). As an example, a decrease from 42 to 21 points would be experienced by an older person who previously reported going out to the neighborhood 4-6 times per week and now can only visit his/her own yard or porch with the same frequency.

We also found that frail older adults had higher odds of having their quality of life affected by restrictions in lifespace mobility. Previous studies have demonstrated that frail older adults have lower levels of perceived autonomy (47). Therefore, it is possible that in a scenario where social distancing recommendations further limited their already constricted autonomy, frail individuals felt more impacted by the COVID-19 quarantine (21). Another vital concern raised by our results was the considerable decrease in regular physical activity. Frailty, sarcopenia, and chronic diseases are just some of the many health problems that can be aggravated by physical inactivity in older people (48). Although the long-term consequences of these abrupt lifestyle changes are still unclear, they are likely to be particularly harmful for the geriatric population (24).

Modern healthcare systems had never been required to adapt to such rigorous and widespread quarantine orders. It quickly became evident that resources such as telemedicine and homebased exercise programs would be critical for maintaining the health of vulnerable populations (49). For instance, our telephone interviews also represent a simple, low-cost, and reproducible strategy to maintain essential aspects of follow-up during the quarantine. They can also be employed to educate patients regarding the COVID-19 pandemic, provide basic health care recommendations, and identify patients requiring additional psychological support (49).

Our work had important strengths. It was a multicenter study conducted in the epicenter of the COVID-19 pandemic in Brazil. Besides, we completed our interviews during the outbreak in Sao Paulo, which allowed us to investigate the realtime consequences of the unexpected scenario. Finally, we were able to adjust our analyses for several possible confounders of the association between life-space mobility and quality of life.

Even so, the study had some limitations. We excluded patients with dementia, limiting the external generalizability of the results. Given that frailty is often associated with other geriatric syndromes, future studies should explore our findings in individuals with cognitive impairment or hearing loss. Also, we asked our patients about their physical activity and lifespace mobility levels before the pandemic, and their answers could have been subject to recall bias. Another possible limitation was our use of a single question to evaluate quality of life during the COVID-19 quarantine. Still, our choices are justified by existing evidence that demonstrates high levels of validity of single-item assessments to capture changes in quality of life associated with specific contexts $(50,51)$. Instead of improving measurements, a multi-domain assessment could confound the dimensionality of outcome with multiple causal sources (39).

In conclusion, we observed substantial decreases in life-space mobility during the COVID-19 quarantine, and we verified that restrictions on life-space were associated with the impact of the quarantine on the quality of life of community-dwelling older adults. Providers should be aware that frail individuals were particularly vulnerable to the effects of restricted life-space mobility on quality of life and explore strategies to minimize their suffering during the COVID19 pandemic. We plan to follow our cohort during the next months to advance our understanding of trajectories of physical and mental health in geriatric patients after the COVID-19 quarantine. 


\section{COVID-19 PANDEMIC AND QUALITY OF LIFE}

Acknowledgments: We would like to thank Juliana de Paula Santoro, Ligia Andressa Sales, Giovanna Caroline de Lima, Raquel Ribeiro de Oliveira, Paola Teruya Ramos, Camila Suemi Higa, Maria Laura Lazaretti Perini, Virgílio Augusto Deodato Gonçalves, and Anna Tereza Bezerra de Menezes Fernandes for completing our telephone interviews.

Ethical standards: The authors declare that the study procedures comply with current ethical standards for research involving human participants and follows the principles outlined in the Declaration of Helsinki. The study protocol was approved by the Institutional Review Board of the four

study sites in Sao Paulo, Brazil.

Conflicts of Interest: All authors declare no conflict of interest to disclose.

\section{References}

1. Dong E, Du H, Gardner L. An interactive web-based dashboard to track COVID-19 in real time. Lancet Infect Dis 2020;20:533-4. doi:10.1016/S1473-3099(20)30120-1.

2. Morley, J.E., Vellas, B. COVID-19 and Older Adult. J Nutr Health Aging. 2020; 24 , 364-365. https://doi.org/10.1007/s12603-020-1349-9

3. Aliberti MJR, Covinsky KE, Garcez FB, et al. A fuller picture of COVID-19 prognosis: the added value of vulnerability measures to predict mortality in hospitalised older adults. Age Ageing 2020. doi: 10.1093/ageing/afaa240.

4. Poco PCE, Aliberti MJR, Dias MB, et al. Divergent: age, frailty, and atypical presentations of COVID-19 in hospitalized patients. J Gerontol A Biol Sci Med Sci 2020. doi: 10.1093/gerona/glaa280.

5. Lewnard JA, Lo NC. Scientific and ethical basis for social-distancing interventions against COVID-19. Lancet Infect Dis 2020;20:631-3. doi:10.1016/S14733099(20)30190-0.

6. Roschel H, Artioli GG, Gualano B. Risk of Increased Physical Inactivity During COVID-19 Outbreak in Older People: A Call for Actions. J Am Geriatr Soc 2020;68:1126-8. doi:10.1111/jgs.16550.

7. Steinman MA, Perry L, Perissinotto CM. Meeting the Care Needs of Older Adults Isolated at Home During the COVID-19 Pandemic. JAMA Intern Med 2020. doi:10.1001/jamainternmed.2020.1661.

8. Berg-Weger, M., Morley, J.E. Loneliness and Social Isolation in Older Adults during the COVID-19 Pandemic: Implications for Gerontological Social Work. J Nutr Health Aging. 2020; 24, 456-458. https://doi.org/10.1007/s12603-020-1366-8

9. Galea S, Merchant RM, Lurie N. The Mental Health Consequences of COVID-19 and Physical Distancing: The Need for Prevention and Early Intervention. JAMA Intern Med 2020. doi:10.1001/jamainternmed.2020.1562.

10. Sepulveda-Loyola W, Rodríguez-Sánchez I, Perez-Rodriguez P, et al. Impact of social isolation due to COVID-19 on health in older people: Mental and physical effects and recommendations. The journal of nutrition, health \& aging. 2020. doi: 10.1007/ s12603-020-1469-2

11. Satariano WA, Guralnik JM, Jackson RJ, Marottoli RA, Phelan EA, Prohaska TR Mobility and aging: new directions for public health action. Am J Public Health. 2012;102(8):1508-1515. doi:10.2105/AJPH.2011.300631

12. Rantakokko M, Portegijs E, Viljanen A, Iwarsson S, Rantanen T. Life-space mobility and quality of life in community-dwelling older people. J Am Geriatr Soc. 2013;61(10):1830-1832. doi:10.1111/jgs.12473

13. Kennedy RE, Almutairi M, Williams CP, Sawyer P, Allman RM, Brown CJ Determination of the Minimal Important Change in the Life-Space Assessment. J Am Geriatr Soc 2019;67:565-9. doi:10.1111/jgs.15707

14. Jacobs JM, Hammerman-Rozenberg A, Stessman J. Frequency of Leaving the House and Mortality from Age 70 to 95. J Am Geriatr Soc 2018;66:106-12. doi:10.1111/ jgs. 15148 .

15. Peel C, Sawyer Baker P, Roth DL, Brown CJ, Brodner E V, Allman RM. Assessing mobility in older adults: the UAB Study of Aging Life-Space Assessment. Phys Ther 2005;85:1008-119.

16. Kennedy RE, Sawyer P, Williams CP, Lo AX, Ritchie CS, Roth DL, et al. Life-Space Mobility Change Predicts 6-Month Mortality. J Am Geriatr Soc 2017;65:833-8. doi:10.1111/jgs.14738.

17. Mackey DC, Lui L-Y, Cawthon PM, Ensrud K, Yaffe K, Cummings SR. Life-Space Mobility and Mortality in Older Women: Prospective Results from the Study of Osteoporotic Fractures. J Am Geriatr Soc 2016;64:2226-34. doi:10.1111/jgs.14474.

18. Mackey DC, Cauley JA, Barrett-Connor E, Schousboe JT, Cawthon PM, Cummings SR, et al. Life-Space Mobility and Mortality in Older Men: A Prospective Cohort Study. J Am Geriatr Soc 2014;62:1288-96. doi:10.1111/jgs.12892.

19. Fathi R, Bacchetti P, Haan MN, Houston TK, Patel K, Ritchie CS. Life-Space Assessment Predicts Hospital Readmission in Home-Limited Adults. J Am Geriatr Soc 2017;65:1004-11. doi:10.1111/jgs.14739.

20. Sheppard KD, Sawyer P, Ritchie CS, Allman RM, Brown CJ. Life-space mobility predicts nursing home admission over 6 years. J Aging Health 2013;25:907-20. doi:10.1177/0898264313497507.

21. Xue Q-L, Fried LP, Glass TA, Laffan A, Chaves PHM. Life-space constriction, development of frailty, and the competing risk of mortality: the Women's Health And Aging Study I. Am J Epidemiol 2008;167:240-8. doi:10.1093/aje/kwm270.

22. Lo AX, Brown CJ, Sawyer P, Kennedy RE, Allman RM. Life-space mobility declines associated with incident falls and fractures. J Am Geriatr Soc 2014;62:919-23 doi:10.1111/jgs.12787.

23. Rantakokko M, Portegijs E, Viljanen A, Iwarsson S, Kauppinen M, Rantanen T. Changes in life-space mobility and quality of life among community-dwelling older people: a 2-year follow-up study. Qual Life Res an Int J Qual Life Asp Treat Care Rehabil 2016;25:1189-97. doi:10.1007/s11136-015-1137-x.

24. Garnier-Crussard A, Forestier E, Gilbert T, Krolak-Salmon P. Novel Coronavirus (COVID-19) Epidemic: What Are the Risks for Older Patients? J Am Geriatr Soc 2020;68:939-40. doi:10.1111/jgs.16407.

25. Wallace M, Shelkey M. Katz Index of Independence in Activities of Daily Living (ADL). Urol Nurs 2007;27:93-4.

26. Harris PA, Taylor R, Thielke R, Payne J, Gonzalez N, Conde JG. Research electronic data capture (REDCap)--a metadata-driven methodology and workflow process for providing translational research informatics support. J Biomed Inform 2009;42:37781. doi:10.1016/j.jbi.2008.08.010.

27. Nelson LM, Simard JF, Oluyomi A, Nava V, Rosas LG, Bondy M, et al. US Public Concerns About the COVID-19 Pandemic From Results of a Survey Given via Socia Media. JAMA Intern Med 2020. doi:10.1001/jamainternmed.2020.1369.

28. Matsudo S, Araújo T, Matsudo V, Andrade D, Andrade E, Oliveira LC, et al. Questionário internacional de atividade física (IPAQ): estupo de validade e reprodutibilidade no Brasil. Rev Bras Atividade Física Saúde 2001;6:5-18.

29. Simões M do SM, Garcia IF, Costa L da C, Lunardi AC. Life-Space Assessment questionnaire: Novel measurement properties for Brazilian community-dwelling older adults. Geriatr Gerontol Int 2018;18:783-9. doi:10.1111/ggi.13263.

30. Baker PS, Bodner E V, Allman RM. Measuring life-space mobility in communitydwelling older adults. J Am Geriatr Soc 2003;51:1610-4. doi:10.1046/j.1532 5415.2003.51512.x.

31. Hughes ME, Waite LJ, Hawkley LC, Cacioppo JT. A Short Scale for Measuring Loneliness in Large Surveys: Results From Two Population-Based Studies. Res Aging 2004;26:655-72. doi:10.1177/0164027504268574.

32. Kroenke K, Spitzer RL, Williams JBW, Löwe B. An ultra-brief screening scale for anxiety and depression: the PHQ-4. Psychosomatics 2009;50:613-21. doi:10.1176/ appi.psy.50.6.613.

33. Apolinario D, Lichtenthaler DG, Magaldi RM, et al. Using temporal orientation, category fluency, and word recall for detecting cognitive impairment: the 10-point cognitive screener (10-CS). Int J Geriatr Psychiatry 2016;31:4-12. doi:10.1002/ gps.4282.

34. Katz S, Akpom CA. A measure of primary sociobiological functions. Int J Health Serv 1976;6:493-508. doi:10.2190/UURL-2RYU-WRYD-EY3K.

35. Saraiva MD, Rangel LF, Cunha JLL, et al. Prospective GERiatric Observational (ProGERO) study: cohort design and preliminary results. BMC geriatrics, 2020;20(1),1-12. doi: 10.1186/s12877-020-01820-4

36. Morley JE, Malmstrom TK, Miller DK. A simple frailty questionnaire (FRAIL) predicts outcomes in middle aged African Americans. J Nutr Health Aging 2012;16:601-8.

37. Bowling A. Just one question: If one question works, why ask several? J Epidemiol Community Health 2005;59:342-5. doi:10.1136/jech.2004.021204.

38. Gill TM, Feinstein AR. A critical appraisal of the quality of quality-of-life measurements. JAMA 1994;272:619-26.

39. Fayers PM, Hand DJ. Causal variables, indicator variables and measurement scales: an example from quality of life. J R Stat Soc Ser A (Statistics Soc 2002;165:233-53 doi:10.1111/1467-985X.02020.

40. Lee SJ, Moody-Ayers SY, Landefeld CS, Walter LC, Lindquist K, Segal MR, et al. The relationship between self-rated health and mortality in older black and white Americans. J Am Geriatr Soc 2007;55:1624-9. doi:10.1111/j.15325415.2007.01360.x.

41. Knol MJ, VanderWeele TJ. Recommendations for presenting analyses of effect modification and interaction. Int J Epidemiol 2012;41:514-20. doi:10.1093/ije/dyr218.

42. Crowe M, Andel R, Wadley VG, Okonkwo OC, Sawyer P, Allman RM. Life-space and cognitive decline in a community-based sample of African American and Caucasian older adults. J Gerontol A Biol Sci Med Sci 2008;63(11):1241-1245. doi:10.1093/gerona/63.11.1241.

43. Kennedy RE, Williams CP, Sawyer P, et al. Life-Space Predicts Health Care Utilization in Community-Dwelling Older Adults. J Aging Health. 2019;31(2):280292. doi: $10.1177 / 0898264317730487$

44. Silberschmidt S, Kumar A, Raji MM, Markides K, Ottenbacher KJ, Al Snih S. LifeSpace Mobility and Cognitive Decline Among Mexican Americans Aged 75 Years 


\section{THE JOURNAL OF NUTRITION, HEALTH \& AGING}

and Older. J Am Geriatr Soc. 2017;65(7):1514-1520. doi:10.1111/jgs.14829

45. Snih S Al, Peek KM, Sawyer P, Markides KS, Allman RM, Ottenbacher KJ. LifeSpace Mobility in Mexican Americans Aged 75 and Older. J Am Geriatr Soc. 2012;60(3):532-537. doi:10.1111/j.1532-5415.2011.03822.x

46. Boyle PA, Buchman AS, Barnes LL, James BD, Bennett DA. Association Between Life Space and Risk of Mortality in Advanced Age. J Am Geriatr Soc 2010;58:192530. doi:10.1111/j.1532-5415.2010.03058.x.

47. Portegijs E, Rantakokko M, Viljanen A, Sipilä S, Rantanen T. Is frailty associated with life-space mobility and perceived autonomy in participation outdoors? A longitudinal study. Age Ageing 2016;45:550-3. doi:10.1093/ageing/afw072.

48. Yamada, M., Kimura, Y., Ishiyama, D. et al. Effect of the COVID-19 Epidemic on Physical Activity in Community-Dwelling Older Adults in Japan: A Cross-Sectional Online Survey. J Nutr Health Aging. 2020. https://doi.org/10.1007/s12603-020-1424-2
49. Flint L, Kotwal A. The New Normal: Key Considerations for Effective Serious Illness Communication Over Video or Telephone During the Coronavirus Disease 2019 (COVID-19) Pandemic. Ann Intern Med 2020. doi:10.7326/M20-1982.

50. Galenkamp H, Deeg DJH, Braam AW, Huisman M. "How was your health 3 years ago?" Predicting mortality in older adults using a retrospective change measure of self-rated health. Geriatr Gerontol Int 2013;13:678-86. doi:10.1111/j.1447 0594.2012.00963.x.

51. de Boer AGEM, van Lanschot JJB, Stalmeier PFM, et al. Is a single-item visual analogue scale as valid, reliable and responsive as multi-item scales in measuring quality of life? Qual Life Res an Int J Qual Life Asp Treat Care Rehabil 2004;13:311-20. doi:10.1023/B:QURE.0000018499.64574.1f. 